\title{
REACTION OF MEDICAL STUDENTS TO EXPERIENCES IN DISSECTION ROOM
}

\section{Dereje Getachew}

\begin{abstract}
BACKGROUND: As preclinical medical students start and/or enter the course, they go through the anatomy curriculum, which involves interaction with cadavers and cadaveric material. The objective of this study was to determine the reactions of preclinical medical students from year two and year three to the dissecting room.

METHODS: Questionnaire was distributed to all second and third year medical students. The questionnaire was designed with the objective of identifying specific patterns of attitudes held and problems faced by the students in their first exposure to the human cadaver. The results are analyzed statistically using the SPSS 16.0 software and $P<0.05$ was considered statistically significant.

RESULTS: The commonest symptoms experienced were loss of appetite (43.29\% year 2 and $34.86 \%$ third year students). The commonest cause of their symptoms was studied and the result shows that it was the smell of the dissection room, as reported by $67.01 \%$ of year two students; and $54.12 \%$ for year 3 students.

CONCLUSION: The present study findings show that smell of the dissection room, touch and fear of cadaver were the commonest cause of their symptoms experienced while study in dissection room for the majority of students. Thus, instructors are should give awareness raising education before the commencement of the dissection session to the students both mentally and emotionally ready to do their work enthusiastically and confidently. Moreover, it is necessary to make the laboratory tidy for the students so that they develop a love for the dissection room.

KEY WORDS: Anatomy, dissecting room, preclinical students, student reactions, stress, learning methods
\end{abstract}

DOI: http://dx.doi.org/10.4314/ejhs.v24i4.9

\section{INTRODUCTION}

The teaching of gross anatomy has, for centuries, relied on the dissection of human cadavers (1). Dissection of human body is incorporated as methods of instruction for anatomy course in medical school of most countries including Ethiopia. Study on human body is almost universally accepted method of education. However, over the last many years attention has been drawn to the traumatic effects of the dissection on some students and the implications of such trauma on subsequent education and practice(2). Previous research shows that work with cadaver is not only distressing, but also rewarding(3). In many researches, aspects of dissection that medical students face are reported to include revulsion at the sight and smell of the cadavers, shock at confronting death, desecration and dismemberment, violation of cultural taboos, dehumanization and invasion of privacy. In the last three decades, anatomists have done research on medical students' reactions, both physiological and emotional, to cadaver dissection. Most of this researches have been carried out overseas particularly in English speaking countries (4).

The aim of this study was to investigate the reactions of preclinical medical students at year

Anatomy Unit, College of Medicine and Health Sciences, Hawasa University

Corresponding Author: Dereje Getachew, Email: getachewdereje68@gmail.com 
two and year three studying at the Hawassa University College of medicine and Health Sciences, to the anatomy dissection room. To find solution: and to compare the findings with the findings of similar studies carried out in Australia, Nigeria, America, Ireland, United Kingdom and Oman (5-9).

There are two best techniques to study human anatomy: observation and visualization(10). For this reason, practical session is highly important. Anatomy is a visual science because it is structural. Anatomical dissection is a stepping stone to understanding the subject matter. Precise dissection of cadaver and examination of dissected specimens are among the major methods of learning anatomy. The anatomy dissection room is also the right place where medical students begin the first step to transfer from laypersons to physicians. Studies done in America on the anatomy room experience have reported that $5 \%$ of students suffer from symptoms suggestive of Post-traumatic Stress Disorders (PTSD) (11). Another study by Penny found that some American students have strong reactions to dissection, and advised that they be adequately prepared for the experience (12). Reports from Britain suggested that such serious distress is rare and the majority of medical students find initial cadaver dissection a significant and challenging life event (13). Studies done in Ireland also showed that $80 \%$ of students suffered very little or no stress on the first visit to the dissection room (9). Conversely, a study of Arab students in Sultan Qaboos University, Muscat, in Oman, found that few of them experienced little level of fear prior and during the first visit of dissecting room practical classes (6).

The medical program in Hawassa University, College of Medicine and Health Sciences, is divided into three phases. Phase 1 consists of the first two years of the program, during which students are taught relevant basic medical sciences (preclinical I and II). Phase 2 involves developing clinical skills (clinical I and II), while in phase 3, students undergo clinical clerkship in the various clinical disciplines-internship program. Second year students (preclinical I) are taught anatomy parallel with dissection of cadaver in separate rooms. The college has medium size dissection room for student practice. The teaching of Anatomy is given parallel with the other basic medical sciences including histology and embryology, but follows regional approach. In Ethiopia, getting cadaver is somehow difficult to obtain for anatomy dissection; hence, limited specimens are used in gross anatomy practical sessions.

\section{METHODS}

Anatomical dissection is a conventional method of learning anatomy for second year preclinical students at Hawassa University, College of Medicine and Health Sciences, School of Medicine, 2011/12. They have three medium-size dissecting rooms in which students of every year used to practice. Every year, the intake of medical students has been almost double of previous year. Almost, on average, each year around 110 medical students attend the lab.

The post-dissection questionnaire also aimed at documenting a student's retrospective selfassessment of the dissection experience, including the physiological and psychological reactions experienced during first exposure to dissection room and after it. The sample size of about 211 students was enrolled in the study, which is the whole group. The list of the students was collected from Registrar Office School of Medicine.

Questionnaire was distributed to all second and third year medical students; only 206 were returned the questionnaire. Of the total students who filled the questionnaires, 97 were year two, and 109 were year three students since September of the academic year 2011-2012 GC.

Enough explanation was given to the students about the main objective and the specific purpose of the research. After the purpose of the study was explained for them, verbal consent was obtained and the subjects' names were not recorded. The data were collected using standard questionnaire prepared in English. The questionnaire was administered by the principal investigator for both sections in the class room at the same time to all students.

At the time of administering the questionnaire, students in year two had completed first semester course of gross anatomy practical sessions, while those in year three had completed the entire program. The questionnaire was designed with the objective of identifying specific 
patterns of attitudinal change and problems faced by the students during their first exposure to the human cadaver. The questionnaire was designed to collect socio-demographic part like age of respondents, their sex, their country of origin, symptoms suffered on first entry to the dissecting room, duration of the symptoms, causes of the symptoms and coping strategies. Rate of stress level in dissection room and other stresses on a numerical scale were also taken. Other questionnaire collected: learning methods, desire/ interest to study medicine, and mental preparedness to study cadaver at the beginning of the course. Data were analyzed statistically using the SPSS 16.0 software and the findings were discussed in comparison with other findings. $\mathrm{P}<$ 0.05 was considered statistically significant.

\section{RESULTS}

The response rate was $83.50 \%(81 / 97 * 100)$ for year two students and $77.98 \%(85 / 109 * 100)$ for year three students. All of the students were Ethiopian. The respondents were 71 males and 10 females from year two, and 54 males and 31 females from year three. The modal age for year two students was 20 years old while it was 21 years old for year three (Table 1).

Table 1: Students' profiles and response rates

\begin{tabular}{lll|rl}
\hline & & Year 2 $(\mathrm{N}=97)$ & \multicolumn{2}{|c}{ Year 3 $(\mathrm{N}=109)$} \\
\hline Modal age ( mean) & & $20(97.2 \%)$ & 21 & $(90 \%)$ \\
Response Rate & & $81(83.50 \%)$ & $85(77.98 \%)$ \\
Sex & Male & $71(73.19 \%)$ & $54(49.54 \%)$ \\
& Female & $10(10.30 \%)$ & $31(28.44 \%)$ \\
Nationality (Ethiopian) & & $81(83.50 \%)$ & $85(77.98 \%)$ \\
\hline
\end{tabular}

Almost $19.58 \%$ of year two and $28.44 \%$ of year three students felt no symptom on first entry into the dissecting room. The commonest symptoms were also loss of appetite $43.29 \%$ for second year and $34.86 \%$ for third year students. $\mathrm{P}<.0 .0001$ was statistically significant for both year 2 and year 3 students. T- Difference $=0.091$ does not show significant. For the remaining students, the commonest symptoms were dizziness $(34.02 \%)$ and nausea $(34.02 \%)$ for second and third year students respectively. Other symptoms reported were breathlessness, irritation of the eye, skin irritation, and one female student expressed having felt sympathetic for the cadaver (Table 2).

Table 2: Symptoms experienced on first entry into the dissecting room

\begin{tabular}{lllll|llll}
\hline Symptoms & \multicolumn{4}{c}{ Year 2 } & \multicolumn{4}{c}{ Year 3 } \\
& $\begin{array}{l}\text { Number of } \\
\text { Respondents }\end{array}$ & M & F & $\%$ & $\begin{array}{l}\text { Number of } \\
\text { Respondents }\end{array}$ & & F & \% \\
\hline Fainting & 7 & 7 & 0 & 7.21 & 1 & 1 & 0 & 0.91 \\
Dizziness & 33 & 27 & 6 & 34.02 & 17 & 14 & 3 & 15.59 \\
Nausea & 33 & 30 & 3 & 34.02 & 29 & 25 & 4 & 26.60 \\
Vomiting & 2 & 2 & 0 & 2.06 & 3 & 3 & 0 & 2.75 \\
Palpitations & 11 & 10 & 1 & 11.34 & 20 & 17 & 3 & 18.34 \\
Sweating & 25 & 21 & 4 & 25.77 & 19 & 15 & 4 & 17.43 \\
Loss & 42 & 40 & 2 & 43.29 & 38 & 30 & 8 & 34.86 \\
appetite & & & & & & & & \\
Insomnia & 13 & 13 & 0 & 13.40 & 6 & 6 & 0 & 5.50 \\
No symptoms & 19 & 16 & 3 & 19.58 & 31 & 14 & 17 & 28.44 \\
Others & 17 & 16 & 1 & 17.52 & 6 & 5 & 1 & 5.50 \\
\hline
\end{tabular}


The commonest cause of their symptoms was the smell of the dissection room, as reported by $67.01 \%$ of second year and $54.12 \%$ third year students respectively. $\mathrm{P}<0.0701$ is not quite statistically significant for year 2 , while $\mathrm{p}<$

Table 3: Cause of symptoms
0.0115 is statistically significant for year 3 students. The findings also show that touch and fear were $31.19 \%$ and $31.19 \%$ for year two and year three students respectively (Table 3 ).

\begin{tabular}{|c|c|c|c|c|c|c|c|c|}
\hline \multirow[t]{2}{*}{ Cause of symptoms } & \multicolumn{3}{|c|}{ Year 2} & \multirow[b]{2}{*}{$\%$} & \multicolumn{3}{|c|}{ Year 3} & \multirow[b]{2}{*}{$\%$} \\
\hline & $\begin{array}{l}\text { Numbe } \\
\mathrm{r}\end{array}$ & M & $\mathrm{F}$ & & $\begin{array}{l}\text { Numb } \\
\text { er }\end{array}$ & M & $\mathrm{F}$ & \\
\hline Smell & 65 & 58 & 7 & 67.01 & 59 & 52 & 17 & 54.12 \\
\hline Sight & 33 & 26 & 7 & 34.02 & 29 & 22 & 7 & 26.60 \\
\hline Touch & 33 & 27 & 6 & 34.0 & 34 & 27 & 7 & 31.19 \\
\hline Fear of infection & 35 & 34 & 1 & 36.08 & 34 & 25 & 9 & 31.19 \\
\hline $\begin{array}{l}\text { Looking at certain parts } \\
\text { of the cadaver }\end{array}$ & 28 & 24 & 4 & 28.86 & 22 & 16 & 6 & 20.18 \\
\hline $\begin{array}{l}\text { Touching certain parts } \\
\text { of the cadaver }\end{array}$ & 19 & 16 & 3 & 17.43 & 29 & 25 & 4 & 26.60 \\
\hline Others & 17 & 17 & & 15.59 & 8 & 7 & 1 & 7.33 \\
\hline
\end{tabular}

The mechanism of focusing on task was the main coping strategy used by $62.88 \%$ of the year two students and $44.95 \%$ of year three students. P < 0.0259 is statistically significant for year 2 while $\mathrm{p}<0.0001$ is extremely statistically significant for year 3. Moreover, for $58.76 \%$ of second year students and $35.77 \%$ of third year students, staying in a group was the coping mechanism used (Table 4). Duration of the symptoms were studied and results show that $28.86 \%$ of year two students and $22.93 \%$ of year three students had symptoms only on the first visit, while $11.34 \%$ of year two students and $4.58 \%$ of year three students had prolonged symptoms up to the time of the study.

Table 4: Coping mechanisms used by the students

\begin{tabular}{|c|c|c|c|c|c|c|c|c|}
\hline \multirow[t]{2}{*}{ Strategies } & \multicolumn{3}{|c|}{ Year 2} & \multirow[b]{2}{*}{$\%$} & \multicolumn{3}{|c|}{ Year 3} & \multirow[b]{2}{*}{$\%$} \\
\hline & Number & $\mathrm{M}$ & $\mathrm{F}$ & & Number & $\mathrm{M}$ & $\mathrm{F}$ & \\
\hline Focusing on task & 61 & 53 & 8 & 62.88 & 49 & 36 & 13 & 44.95 \\
\hline Praying & 29 & 27 & 2 & 29.89 & 23 & 17 & 6 & 21.10 \\
\hline Relaxation & 53 & 48 & 5 & 54.63 & 31 & 22 & 9 & 28.44 \\
\hline Staying in a group & 57 & 50 & 7 & 58.76 & 39 & 27 & 9 & 35.77 \\
\hline $\begin{array}{ll}\text { Advice } & \text { from } \\
\text { lecturers } & \end{array}$ & 36 & 34 & 2 & 37.11 & 30 & 24 & 30 & 27.52 \\
\hline Others & 11 & 11 & 0 & 11.34 & 5 & 3 & 2 & 4.58 \\
\hline
\end{tabular}

Table 5 shows that stress rating on a numerical scale was about $59.79 \%$ for year two students while it was $44.95 \%$ of year three students who found the anatomy dissection room very stressful. However, in comparison, examinations were much more stressful, according to $78.35 \%$ of year two students and $71.55 \%$ of year three students.
Preferences of their learning methods were also studied. This study found that a round $70.10 \%$ of year two students were prefer textbooks and $58.71 \%$ of year three students were prefer practical sessions as one of their best learning methods. 
Table 5: Stress rating on a numerical scale

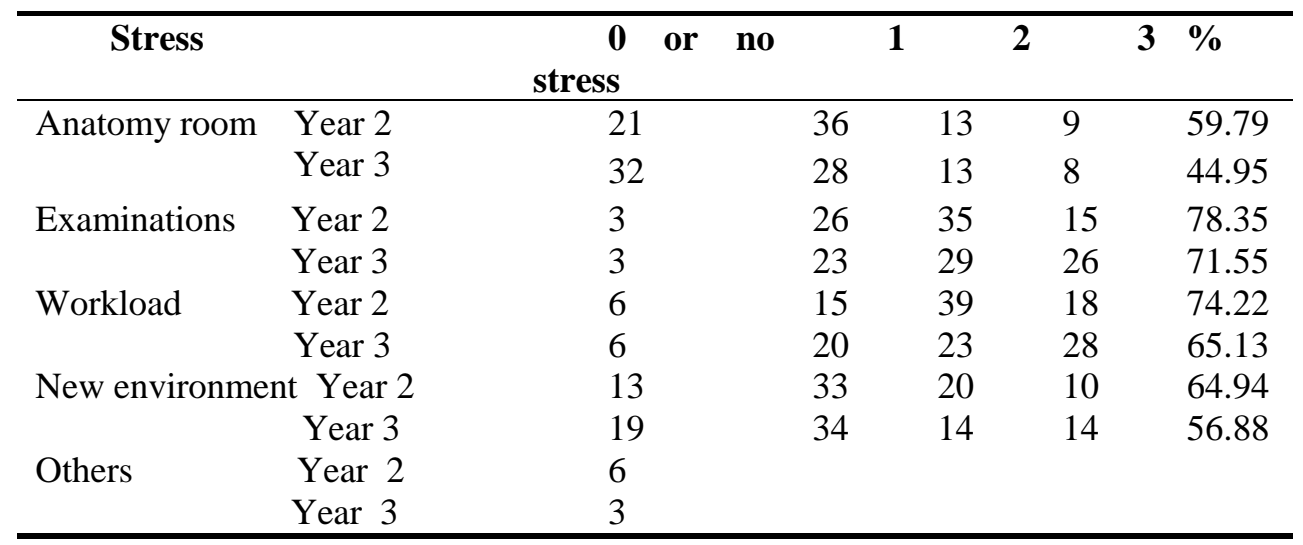

Table 6 shows that the majority of students considered that they were mentally ready to study in the dissecting room at the commencement of their studies $(56.70 \%$ year two and $62.38 \%$ year three students).

Table 6: Mental preparedness to study cadaver

\begin{tabular}{lllll}
\hline Options & $\begin{array}{l}\text { Year 2 } \\
\text { Number }\end{array}$ & \% & $\begin{array}{l}\text { Year 3 } \\
\text { Number }\end{array}$ & \% \\
\hline Yes & 55 & 56.70 & 68 & 62.38 \\
No & 9 & 9.27 & 9 & 8.25 \\
Not & 17 & 17.52 & 7 & 6.42 \\
answer & & & & \\
\hline
\end{tabular}

Correlation /association (cor.coef.) between second year and third year students regarding the symptoms experienced on first entry into the dissecting room is 0.779 . This shows that there is a strong positive relationship between the two groups. The correlation /association (cor.coef.) is 0.918 between second year and third year students about the causes of symptoms. This shows that there is a strong positive relationship between the two groups. The correlation/association (cor.coef.) is 0.944 about the coping mechanisms used between year 2 and year 3 students. Again, this shows that there is a strong positive relationship between the two groups. So, the findings show that there is a basic similarity between the two batches in terms of their experience in the dissection room and the way they try to resolve the problem.

\section{DISCUSSION}

The response rate was $83.50 \%$ (81/97) for year two students and $77.98 \%(85 / 109)$ for year three students. Out of these, $73.19 \%$ were males and
$10.30 \%$ was females for year two students; $49.54 \%$ were males and $28.44 \%$ were females for year three students (the respondent were 71 males and 10 females from year 2, and 54 male and 31 females from year 3). All of the students were Ethiopians. The present study results show that $19.58 \%$ of year 2 students and $28.44 \%$ of year 3 students felt no symptom on first entry into the dissecting room. For the majority of the students, both in year two and year three, loss of appetite was one of the commonest symptoms. Other temporary symptoms like dizziness (34.02\%) and nausea (34.02\%) students were experienced by second and third year students respective. However, Horne at al. (5) reported that $30 \%$ of Australian students showed physical symptoms on first exposure to cadavers in the dissecting room. Moreover, the study on Arab medical students in Sultan Qaboos University in Muscat, Oman, showed that $46 \%$ of their students experienced some levels of fear before and during the initial dissecting room practical session (6). Other symptoms reported were breathlessness, irritation of the eye, skin irritation, and one female student also indicated that she felt sympathetic for the cadaver.

The commonest cause of their symptoms was studied. The smell of the dissection room was the common cause of symptoms as reported by $67.01 \%$ of year two students. Touch and fear was the common cause of symptoms as reported by $31.19 \%$ of year three students. This study in line with other such as with Arab students which was $91 \%$ (6). As recommendation it needs to improve tidy of the dissecting room.

Regarding the extent of symptoms, about $28.86 \%$ of year 2 student and $22.93 \%$ of year 3 students had symptoms only on the first visit, while $11.34 \%$ of year 2 students and $4.58 \%$ of year 3 students had symptoms prolonged up to the time of 
the study. This was very high when compared with other studies. In Malaysia, a study showed that $4.3 \%$ of year 1 students and $9.1 \%$ of year 2 students found the dissecting room a most stressful place while the majority rated the stress level as "mild" and "moderate". Among the 11 students who rated the anatomy room a most stressful place, only one student reported prolonged symptoms persisting to the time of the questionnaire-based study. The rest of the students stated that they had no symptoms at all on first entry into the dissecting room (8).

The main coping mechanism used by the students was studied and the result showed that focusing on task was the main coping strategy used in $62.88 \%$ of the year 2 students and $44.95 \%$ of year 3 students. Moreover, for $58.76 \%$ of second year and $35.77 \%$ of third year students; staying in a group was the coping mechanism used too. In comparison, the most frequent method of coping with such fears amongst our students was relaxation $(48.6 \%$ in year 1 and $44.4 \%$ in year 2 students) in Malaysia. The most frequent method of coping in Arab students was rationalization $(65 \%)$, while relaxation used by $39 \%$ (6).Despite, Australian students coping mechanism was discussion with fellow students, friends and family(5).

Stress rate showed that $59.79 \%$ of year 2 students and $44.95 \%$ of year 3 students found the anatomy dissection room very stressful. However, in comparison, examinations were much more stressed, according to $78.35 \%$ of year 2 students and $71.55 \%$ of year 3 students. This study found that a round $70.10 \%$ of year two students were prefer textbooks and $58.71 \%$ of year three students were prefer practical sessions as one of their best learning methods.

The majority of the students had great desire to study medicine. The majority of the students considered that they were mentally ready to study in the dissecting room at the commencement of their studies $(56.70 \%$ in year 2 and $62.38 \%$ in year 3$)$. But, still it needs to do more in order to make the students to love dissection room and to be best medical profession.

\section{ACKNOWLEDGMENT}

I would like to express my sincere thanks to Hawassa University, Research Directorate Office for their trust and funding the research to take place. Moreover, I would also like to extend my thanks to the subject who volunteered to fill the questionnaire properly, and greatly appreciate others who are not mentioned by their name but who have helped for the fulfillment of the study in various ways.

\section{REFERENCES}

1. Williams AD GE, Soricelli RL, Depace DM. Medical students' reactions to anatomic dissection and the phenomenon of cadaver naming. Anatomical sciences education 2013;10.

2. Dene Hancock MW. Impact of cadaver dissection on medical students. New zealand journal of psychology 2004; 33(1).

3. Robbins BD tA, Innus C, Patterson J, Styn G. Lessons from the dead: the experiences of undergraduates working with cadavers. Omega 2008; 58(3):177-92.

4. L.A. Arraez-Aybar, GC-caIC-M. Astudy of cognitive-affactive and physiological-motor reactions to human dissection in spanish students of human anatomy. Eur J Anat. 2007;11:67-71.

5. Horne DJ TJ, Eizenberg N, Tashevska M, Biddle N. Reactions of first year medical students to their initial encounter with a cadaver in the dissecting room. Academic medicine 1990; 65:645-6.

6. Abu-Hijleh MF HN, Moqattash ST, Harris P F, Heseltine GFD. Attitudes and reactions of Arab medical students to the dissecting room. Clin Anat 1997;10:272-8.

7. Dinsmore Charles E SD, Howard J. Zeitz. Students Response to the gross anatomy laboratory in medical curriculum. Clinical Anatomy 2001; 14:231-6.

8. Evans EJ FG. The dissecting room: reactions of first year medical students. Clinical Anat. 1992;5:311-20.

9. MC Garvey MA FT, Conroy R.M, Kandiah S, Monkhouse WS. Dissection: A positive Experience. Clinical Anatomy 2001; 14:227-30.

10. Richard L Drake, wayne Vogl, Adam W.M Mitchell. Gray's anatomy for students. $39^{\text {th }}$ edition. Churchille Livingstone, 2007: 2

11. Finkelstein P ML. Post-traumatic stress among medical students in the anatomy dissection laboratory. Clinical Anat 1990;3:219-26.

12. JC P. Reactions of medical students to human dissection. J Med Edu 1985;60:58-60.

13. O'Carroll RE WS, Jackson D, Sinclair DW. Assessing the emotional impact of cadaver dissection on medical students. J Med Edu 2002; 36: 550-4. 